\title{
Nutrition as a sociological phenomenon
}

\author{
Konstantin Olkhovikov ${ }^{1}$, Lyudmila Zhuravleva ${ }^{2}$, Nisha Kant Ojha ${ }^{3}$, Elena Zarubina ${ }^{2}$, and \\ Aleksey Ruchkin ${ }^{2 *}$ \\ ${ }^{1}$ Ural Federal University named after the first President of Russia B.N.Yeltsin, Department of \\ Sociology and Technology, 62000219 Mira street, Yekaterinburg, Russia \\ ${ }^{2}$ Ural state agrarian University, Institute of Economics, Finance and Management, 620075 ul. Karl \\ Liebknecht, 42, Yekaterinburg, Russia \\ ${ }^{3}$ Sharda University, Department of Information Technology \& Business Analytics, \\ 201310 Plot No. 32-34, Knowledge Park III, Greater Noida, Uttar Pradesh, India
}

\begin{abstract}
The article deals with the theoretical and methodological and procedural foundations of nutrition sociology as a special sociological theory. The authors undertake an analysis of the conducted intelligence sociological research using qualitative methodology. The conclusion is made about the formation of the youth style of food as one of the elements of the youth lifestyle with a pronounced bias towards globalized standards of rationalization of life, combining leisure with food, speeding up the pace of life and gravitation to fast food and other unhealthy products.
\end{abstract}

\section{Introduction}

The quality and availability of food products are the key to the country's food security and a necessary condition for public health [1]. This circumstance determines the research activity of scientists, prompting the analysis of nutrition as a social phenomenon and a process that affects the quality of human potential. The sociology of nutrition is based on data from a number of Sciences, both social and humanitarian, and natural Sciences, for a comprehensive understanding of nutrition as a factor in maintaining health and increasing life expectancy.

Nutrition as a socio-cultural phenomenon and process, which includes a system of relations and routine practices in production, logistics, established marketing communications and rituals of food consumption in various socio-cultural spheres, is the subject of study of the sociology of nutrition as a special sociological theory. It is no accident that the world academic community, represented by the International sociological Association, considers it possible to consider agricultural sociology and nutrition sociology as one inseparable and closely interrelated research area - "Agricultural Sociology and Nutrition Sociology".

The main purpose of the article is to analyze the theoretical-methodological and methodological-procedural foundations of nutrition sociology as a special sociological theory closely related to agricultural sociology and spun off from it during the differentiation of scientific knowledge. To test the hypothesis about the formation of youth

\footnotetext{
* Corresponding author: alexeyruchkin87@gmail.com
} 
eating style and contradictory attitudes of young people regarding healthy food, an intelligence-based sociological study was conducted based on a qualitative strategy for collecting primary information.

\section{Method}

At the first stage of the research, the empirical basis was sociological essays on a defined range of issues aimed at self-analysis of routine food practices of students.

The respondents were students of the Ural state agrarian University, studying at the faculty of biotechnology and food engineering in the specialty "animal food", which we consider as an expert group within the youth audience.

At the second stage, we conducted 4 focus groups with students of various specialties of the Ural state agrarian University.

To understand modern conceptual approaches to nutrition as a social phenomenon, we will briefly focus on the ideas of the sociologists who founded the sociology of nutrition.

The sociological analysis of nutrition as a social action and social stratification factor was undertaken at the beginning of the last century and presented in the work of the founder of the formal sociological school, Georg Simmel. In the work "the Sociology of the meal", written in 1910, a German sociologist defined the meal as an urgent need for all people, since "all of them must eat and drink" to continue life [2, p. 187].

Nutrition in the interpretation of G. Simmel is an element of culture and an action that is regulated in society, prescribing to people: what they should consume, how regularly and in what social environment. According to Simmel, important importance is given to the etiquette and aesthetics of the meal, turning it into a socializing process and a marker of the social status of the individual.

According to the sociologist, "in the lower classes, where the meal is mainly centered around the materiality of food, no typical regulations concerning table manners are developed" [2, p. 189]. While in privileged groups, institutions of joint meals are formed as stable value-regulatory codes that regulate the rules of behavior at a joint table: "how to hold a knife and fork and what topics are suitable for table conversations" [2, p. 189].

In the work" sociology of the meal " Simmel concluded that through the aestheticization and ritualization of the meal in the higher layers, the primitive physiological need forms communicative connections and rises to the level of spiritual attractiveness of food as a socio-cultural action and identification factor.

The analysis of the social function of nutrition and the impact of the effects of mass starvation on social destabilization was continued in the work of P. A. Sorkin "Hunger as a factor. The influence of hunger on human behavior, social organization, and social life" (1922) [3]. P. A. Sorokin's study "the social role of nutrition in General and hunger in particular" describes the consequences of the famine of the 20 s of the last century, which he witnessed. According to the scientist, there is a correlation interdependence in society between the fluctuation of the nutrition curve of society and the variation of ideology and public mood. P. A. Sorokin considered the main social function of nutrition to be the function of social reproduction and social order, and interpreted food shortage as a factor that provokes deviant behavior (primarily, crime and social protests).

Two sociologists G. Simmel and P. A. Sorokin can be called without exaggeration the founders of the sociology of nutrition as a special sociological theory that studies the complex of social problems and social relations that arise in the process of production, distribution, exchange and consumption of food.

Among the representatives of modern sociology, we will highlight the approach to the analysis of nutrition by Pierre Bourdieu, presented by him in his work "Differences: a social critique of judgment". The French sociologist determined the attitude of people to 
nutrition by the habitus (system of preferences and predispositions) of the group to which they belong in the social stratification space of society [4, p.29]. In Accordance With Clause Bourdieu, routine eating practices are an integral symbol of social status and a sign of group identity, turning the process of eating into a social construct and value activity in the"social field".

The established tradition of sociological analysis of nutrition as a stratification marker and criterion for group identification formed the basis of the study "Nutrition in youth assessments"conducted by the authors. The choice of young people as an object of study is explained by the fact that this social community is not just a socio-demographic, but also a socio-cultural group of society with its own style of behavior, similar cultural norms, ideas, ideals and values.

\section{Study detail and result}

According to the world health organization (who), human health primarily depends on lifestyle, which includes nutrition models that strengthen the immune system and are aimed at preventing diseases $[5,8]$. Do modern young people share these ideas, what are their food preferences and daily consumer practices? The answers to these questions were obtained by analyzing 20 sociological essays and using data from focus groups.

Our results revealed contradictory attitudes regarding healthy nutrition of students and are confirmed by our previous research [6]. While studying at the faculty of biotechnology and food engineering, students receive information on food quality during the educational process, and are well aware of harmful additives and non-ecological food products, as well as their impact on human health. At the same time, they regularly use "food garbage", semifinished products, fast food and other delicious, from their point of view, but not useful products. Not coincidentally, the average daily meals, which made the students at their usual 5-point scale, where 1 - lowest, 5 - highest, was 2.9. The results obtained are comparable with the data of the project "Bayer Barometer" of the all-Russia centre of studying of public opinion (VTSIOM), devoted to the study of the diet of Russians, which showed that the nutritional properties of products are important only for $6 \%$ of the respondents [7].

The results of the study allowed us to draw a conclusion about the formation of a special youth style of consumption and nutrition in our country, which is characterized by:

- "McDonaldization" of consciousness (George Ritzer's term, proposed in the book "McDonaldization of society") - orientation to fast food restaurants (McDonald's, Burger King, Subway, KFC, etc.) as a convenient and comfortable place to communicate with friends from the point of view of most students, fairly regular consumption of fast food (burgers, cheeseburgers, hamburgers, French fries and Cola as the main products and drinks offered in these institutions), as well as food on the go in order to "to have time everywhere" and the use of semi-finished products ("Doshirak-my friend» - it was written by one of the students who lives in the hostel);

- the limited resources of young people are one of the factors that affect the insufficient quality of food (choosing mainly "promotional" products with discounts in stores and focusing on products of a lower price category as a common practice of independent purchases);

- irregular eating - as one Respondent wrote "sometimes I don't eat all day, only in the evening I manage", most students described the practice of two meals a day (in the morning and in the evening, with a snack on the go at lunch);

- consumption of "food garbage" - unnatural foods with low nutritional content and harmful artificial additives, but high caloric content, the leaders of consumption according to students are-chips, popcorn ("satellite movie views") and sweets; 
- globalization of food - a trend that is typical mainly for domestic students: eating gastronomic dishes from other cultures and national cuisines: pizza, pasta with seafood, rolls, sushi, other food products of European and Asian cuisine, preference for international fast food chains.

In addition, we have identified different nutrition models for students from domestic and foreign countries (from Uzbekistan and Tajikistan). According to our data, the second group of students is more focused on national cuisine (pilaf, Basma, barbecue) and less focused on eating out.

Different nutrition practices were found in students who live with their parents and separately. In the first case, respondents are more highly valued home-cooked meals compared to eating out. Due to their economic vulnerability and lack of self-selection skills, students who live separately eat less well, are more likely to practice meals in public catering or consume fast food products.

According to respondents, gender differences in nutrition are insignificant: both in clothing and behavior, and in the process of eating, young people are guided by the "unisex" style and do not see differences in the diet of men and women. At the same time, gender differences are shown in discussions about who usually cooks food. Male respondents wrote that" usually cooking is done by a mother or a girl."

During the focus groups, the trends we identified were confirmed. In addition, the group discussion of this problem and reflection on routine food practices were evaluated by the respondents as the first step in the formation of a healthy food culture in each of the group members (the formation of attitudes to minimize the use of food waste and control of the diet). Among the suggestions made by students, we note the following:

1. introduction of elective classes on healthy balanced nutrition and slow food culture;

2. conducting master classes at the University on mastering the culinary skills of preparing traditional dishes of Russian cuisine;

3. within the disciplines of the Humanities cycle, increase attention to the problems of etiquette, feast rituals and other issues of healthy food culture.

\section{Discussion}

The sociology of nutrition is inextricably linked with agricultural sociology, while retaining its subject and relevant research methods. The most effective methods of collecting sociological information in the study of nutrition of various social groups, in our opinion, are the analysis of personal documents (diaries of nutrition, sociological essays analyzing individual nutrition practices), written surveys with the use of projective methods and the predominance of open questions, as well as homogeneous focus groups.

Among the trends recorded by us, we will highlight the following main ones:

- low level of respondents ' nutrition management skills and assessment of the quality of purchased products and their health benefits;

- contradictory patterns of behavior of students regarding the use of healthy food; gaps in values and routine food practices;

- the variety of interpretations of the concept of "healthy food" and the lack of young people's attitude to food as a ritual;

- formation of a youth food style as one of the elements of a youth lifestyle with a pronounced bias towards globalized standards of rationalization of life, combining leisure with food, speeding up the pace of life and gravitation to fast food and other unhealthy (but delicious, enjoyable) products.

After conducting an intelligence study, we tested a number of techniques and received information to continue studying nutrition as a social phenomenon. Taking into account the practical significance of this problem, the research group based on the network interaction 
of universities in the Ural region and India developed a program of an initiative crosscultural sociological research on the topic "youth nutrition Culture", the purpose of which is to analyze the cultural and global food preferences of young people as an innovative group of society. Since food culture is formed by interaction with the social context, a comparative study is planned in two countries-Russia and India. Based on the position that culture has individualized and national forms, the task is to identify immanent universals, to determine the General and special in the culture of nutrition of young people in different countries.

\section{References}

1. L.A. Zhuravleva, T.I. Kruzhkova, L.A. Konopleva, T.V. Lazutina, Food security: challenges and threats, In the collection: Anti-crisis mechanisms in the conditions of economic transformation: a new social contract: Proceedings of the international scientific and practical conference, 6-8 (2018) (In Russ.)

2. Georg Simmel, Sociology: theory, methods, marketing, 4, 187-192 (2010) (In Russ.)

3. P.A. Sorokin, Hunger as a factor, The influence of hunger on human behavior, social organization and social life (Moscow: Akademiya, 2003) (In Russ.)

4. P. Bourdieu, Economic sociology, 6, 3 (2011) (In Russ.) https://ecsoc.hse.ru/data/2011/12/08/1208204931/ecsoc_t6_n3.pdf

5. Global strategy on nutrition, physical activity and health (2018) https://www.who.int/dietphysicalactivity/publications/trs916/en/

6. A.M. Tikhomirova, L.A. Zhuravleva, T.I. Kruzhkova, Ecological consciousness as a factor in consumer behavior of young people in the context of new industrialization: sociological research experience, Proceedings of the 2nd International Scientific conference on New Industrialization: Global, national, regional dimension (SICNI 2018). Part of series Advances in Social Science, Education and Humanities Research. https://www.atlantis-press.com/proceedings/sicni-18/55911906 (2019)

7. Russians proceed from stereotypes when choosing food products, Mode of access (2019) (In Russ.) https://www.bayer.ru/media/news/20191201-products.php

8. A.G. Svetlakov, Agrarian Bulletin of the Urals, 1(180), 66-71 (2019) (In Russ.) 